\title{
Effects of Urbanization on the Aquatic Fauna of the Line Creek Watershed, Atlanta - A Satellite Perspective
}

\author{
Robert R. Gillies ${ }^{\mathrm{a}}$, Jayne Brim Box ${ }^{\mathrm{b}}$, Jürgen Symanzik ${ }^{\mathrm{c}}$, and Eli J. Rodemaker ${ }^{\mathrm{d}}$
}

${ }^{a}$ Department of Plants, Soils and Biometeorology, Department of Aquatic, Watershed and Earth Resources, Utah State University, Logan, UT 84322-4820

${ }^{\mathrm{b}}$ Department of Aquatic, Watershed and Earth Resources, Utah State University, Logan, UT $84322-5210^{2}$

${ }^{c}$ Department of Mathematics and Statistics, Utah State University, Logan, UT 84322-3900 ${ }^{3}$

${ }^{\mathrm{d}}$ Marshall and Associates, Inc., Olympia Office, 1603 Cooper Point Road NW, Olympia, WA $96502-8325^{4}$

\begin{abstract}
Impervious surface area (ISA) was derived for a period from 1979 to 1997 from Landsat MSS and TM data for the Line Creek watershed that lies to the south of the city of Atlanta, Georgia. The change in ISA is presented as an ecological indicator to examine the cumulative water resource impacts on mussel population in three sub-watersheds of Line Creek - namely Line, Flat, and Whitewater creeks. The satellite analysis shows that ISA expansion occurred substantially from 1987 to 1997 and is predominantly in industrial, commercial, and shopping center (ICS) complexes but also in smaller lot-size residential development. Evidence of mussel habitat degradation is indicated and loss of species (in the region of 50 to 70\%) is present in areas where ISA expansion is observed - specifically in ICS complex development in and around Peachtree City that drains directly into the Line and Flat creeks. This is in marked contrast to Whitewater Creek where overall development of ISA is less and no major loss of mussel species is observed.
\end{abstract}

Keywords: Impervious surface area, Landsat, Mussels, Urbanization

\footnotetext{
${ }^{1}$ Corresponding author. Tel: +1-435-797-2664; fax +1-435-797-4048. E-mail address: rgillies@ @n.usu.edu

${ }^{2}$ Tel: +1-435-797-2517; fax +1-435-797-1871. E-mail address: jayne_brim_box@usgs.gov

${ }^{3}$ Tel: +1-435-797-0696; fax +1-435-797-1822. E-mail address: symanzik@ math.usu.edu

${ }^{4}$ Tel: +1-360-352-1279; fax +1-360-357-9903. E-mail address: erodemaker@marshallgis.com
} 


\section{Introduction}

Over 20 years ago Jackson and McCuen (1979) recognized the potential of remote sensing for collecting data to estimate hydrological model parameters over an urban watershed. A critical ongoing environmental issue, very much related to urban development, is that of nonpoint source (NPS) pollution (Todd et al., 1989). However, the interrelationships between compounding factors like rates of growth, type of urbanization, and associated NPS are complex and what is more important, difficult to ascertain spatially. In other words, it is challenging to assess, in a spatially representative way, the combined effects of pollutants, petrochemicals and bacteria that may constitute the run-off from an area of urbanized land. An ecological indicator that integrates such aforementioned cumulative resource impacts, without regard to specific factors, is impervious surface area (ISA).

As urbanization progresses over a watershed any subsequent runoff is altered in both time and magnitude, though interestingly, not to the same extent (Hollis, 1975) as the degree of urbanization. Nevertheless, increases in runoff volume and discharge rates cause physical changes to stream channels (Hammer, 1972). Streambeds are scoured due to higher velocities and stream channels become deepened and/or widened (Booth, 1990). This results in habitat alterations to both in-stream and ${ }^{5}$ riparian zones and the loss of critical aquatic habitats (e.g., riffles). Furthermore, an increasingly problematic aspect of ever-increasing ISA in watersheds is the amount of non-point source pollution delivered to water systems.

Stream environments are some of the most fragile, degraded, and threatened environments in the world due to the strong interactions between aquatic and terrestrial environments and to the human disturbances that can affect either system. Not surprisingly, some of the most endangered plants and animals in the United States live at least part of their lives in freshwater environments (Nature Conservancy, 1996). Despite this, the biological diversity crisis of aquatic systems is poorly understood.

North America, north of Mexico, harbors the greatest freshwater ${ }^{6}$ mollusk biodiversity in the world, as well as the highest percentage of imperiled or extinct species (Williams et al., 1993). The most endangered faunal group in North America is freshwater mussels with extinction rates an order of magnitude higher than expected background levels (Nott et al., 1995; Bogan, 1993). Freshwater gastropods may be experiencing extinction at higher rates than freshwater bivalves, although data are lacking (A. Bogan, pers. comm., North Carolina State Museum of Natural History). Four genera of North American gastropods consisting of 42 species are believed extinct. Within North America, the southeastern United States has more freshwater mussel species than any other region, as well as the majority of the imperiled North American mussel fauna (Neves et al., 1997).

Six factors have been identified as critical vectors of species loss in ${ }^{7}$ lotic environments: habitat loss and degradation, the spread of exotic species, over-exploitation, secondary extinctions, chemical and organic pollution, and climate change (Allan and Flecker, 1993). Although a variety of threats characterize the past century of decline of freshwater mollusks, habitat destruction is one of the most important (Brim Box and Mossa, 1999; Bogan, 1993;

\footnotetext{
${ }^{5}$ riparian zone - the banks of a river, sometimes called the wetlands that run next to and parallel to a river channel.

${ }^{6}$ mollusks - freshwater mussels of the Class Bivalvia and freshwater snails of the class Gastropoda.

${ }^{7}$ lotic - habitats like rivers and streams, running waters.
} 
Williams et al., 1992; Williams et al., 1993). Habitat degradation can result from direct changes to river channels such as damming, dredging, and harvesting mussels for commercial use (e.g., for the Japanese pearl industry), and by indirect changes resulting from activities on interfluves and floodplains such as agricultural activities, logging, urbanization, and road construction (Brim Box and Mossa, 1999; Bogan, 1993; Butler, 1993; Williams et al., 1992).

Attempts to address causal factors of mollusk declines are hampered by a lack of information of life histories, ecology, distributions, fish hosts (all ${ }^{8}$ unionid mussels require a specific host fish to complete their life cycles), and systematics of freshwater mollusks (Bogan, 1993). In addition, the ${ }^{9}$ biotic and ${ }^{10}$ abiotic attributes that define suitable habitats for individual mollusk species are not well known. Moreover, although decreases in freshwater mollusk populations can sometimes be attributed to specific factors (e.g., dams and pollution), much of the information that links mollusk declines to changes in their physical habitats is based on anecdotal or descriptive information (Neves et al., 1997; Williams and Neves, 1995; Bogan, 1993; Fuller, 1974).

Many of the factors (e.g., changes in sedimentation regimes and water quality) that have been qualitatively implicated in the decline of the North American freshwater mollusk fauna are the direct result of land-use changes within the surrounding watershed. River responses (e.g., changes in sediment loading and discharge) to changes in land-use patterns have been well documented (Ligon et al., 1995; Harris and Gosselink, 1990; Newbury, 1984; Fontaine and Bartell, 1983), and the spatial composition of different land uses within a watershed can have a direct effect on surface water quality. For example, in two watersheds with similar agricultural land use, the watershed with a forested riparian zone had higher water quality (i.e., lower turbidity and nutrient runoff) than the watershed where the riparian zone had been deforested (Hunsaker and Levine, 1995).

We know of no studies that have examined changes in ISA and declining mollusk populations. Yet these types of studies have significant potential to provide insight into the future monitoring of mussel populations and possible causes of decline, in part because mussel communities are structured by basin-level characteristics (Strayer, 1983), and because methods to calculate ISA directly from remote sensing data have only recently been developed. In addition, the majority of endangered mussel species occur in the southeastern United States, which contains some of the fastest growing urban areas in the nation (e.g., Atlanta).

This paper examines land-use change with declining mussel populations for the Line Creek watershed, near Atlanta, Georgia, Figure 1. Historically, Line Creek contained a rich mussel (Bivalvia:Unionidae) fauna that included four species that are federally protected and a fifth species now considered extinct (Brim Box and Williams, 2000). Mussel records from Line Creek date back to the 1800 s, but recent surveys suggest its mussel fauna is in decline. We analyze patterns of species declines with changes in the physical characteristics of the Line Creek watershed that accompany those declines through the calculation and temporal depiction of ISA. ISA is computed using remotely sensed imagery from the Landsat platforms (MSS \& TM) spanning three points in time $(1979,1987$, and 1997).

\footnotetext{
${ }^{8}$ unionid - freshwater mussels of the phylum Mollusca, class Bivalvia and order Unionidae. Almost 300 species of unionid mussels are found in the freshwater rivers of North America.

${ }^{9}$ biotic - the living components of an ecosystem.

${ }^{10}$ abiotic - the non-living (or physical) components of an ecosystem.
} 


\section{Methods}

\section{Study Area and Hypotheses}

Line Creek is a major tributary of the Flint River in Georgia. Its headwaters lie just southwest of Atlanta. The Line Creek watershed shown in Figure 1 (approximate area $557 \mathrm{Km}^{2}$ ) comprises three distinct sub-watersheds; namely Line Creek, Flat Creek (emanating from Lake Peachtree), and Whitewater Creek. Figure 2 shows the break out of these individual subwatersheds together with the entire Line Creek watershed. Peachtree City is the main metropolitan area in the Line Creek watershed with an estimated population of 32,321 on 7/1/1999, up from a population estimate base of 18,993 in 4/1/1990 (U.S. Census Bureau, 2000) http://www.peachtree-city.org.

We were interested in examining the entire Line Creek in term of overall urban development and ecological impact. In addition, the sub-watersheds of Line / Flat and Whitewater creeks might offer further insights from two perspectives: First, the urban development of the Line / Flat watershed as compared to the Whitewater Creek watershed is markedly different in extent and magnitude, so we might realistically find differences in aquatic decline between the two sub-watersheds. Second, the confluence of Line and Flat creeks (where study sites $\mathrm{F}$ and $\mathrm{K}$ reside) is where we might reasonably expect to observe a greater ecological impact due to component flows from these two creeks (Morisawa and LaFlure, 1979).

\section{Mussel Surveys}

Mussel surveys in 1992, 1995, 1997, and 1999 were conducted using timed searches. This technique has been shown to be effective when the object of a survey is to find the majority of mussel species present, as well as rare species (Strayer et al., 1997; Vaughn et al., 1997). All mussels were collected by hand using either SCUBA, snorkeling, or by direct observation in shallow areas. All possible habitats where mussels could occur were checked, including root mats, rock crevices, logs, vegetation, etc. The presence of all mussels encountered and their relative abundance were recorded for each site. Each site (labeled A through P in Figure 1) was sampled until no new species were found or all potential habitats where mussels could occur were surveyed. A minimum of one-person hour was spent at each site.

Historical records (i.e., pre-1992) from Line Creek were collected as part of a larger study of mussels in the Apalachicola River basin (Brim Box and Williams, 2000). In that study, a thorough literature and museum search was conducted to obtain published and unpublished records of mussels from Line, Flat and Whitewater sub-watersheds.

\section{Area Delineation and ISA Determinations}

Landsat imagery was used to derive ISA. Three Landsat images (1979, 1987 and 1997) were georeferenced to a common UTM map base and subsequently calibrated to apparent reflectance. The first major step in the spatial analysis was the delineation of the Line Creek watershed first order boundaries. This was done in ARCView using both digital elevation models and digitized hydrography for the region. Using these data and ARC routines (watershed, flowdirection, and selectpoint), a pour point, specified in UTM coordinates, was selected that was successful in "filling-in" the entire drainage area. The resulting grid file was converted to a vector file and the vector file was used in ERDAS Imagine ${ }^{\circledR}$ to generate an area-of-interest (AOI) subset. 
The sub-watersheds (Line, Line / Flat and Whitewater) were extracted in exactly the same manner.

The theory, adopted here, behind the satellite determination of ISA is based upon the observation (Jennings and Jarnagin, 2000; Ridd, 1995; Klein, 1979; Leopold, 1973) that ISA is inversely related to vegetation cover in urban areas, i.e., non-vegetated surfaces in urban areas are almost entirely impervious in North American cities. In making this assumption it is also assumed that no impervious surfaces reside in areas that are not developed. The estimation of ISA from satellite-based reflectivity data therefore relies upon the calculation of two surface parameters namely, the fraction of vegetation coverage in a pixel and those pixels that are developed.

The developed areas were defined by applying hybrid classification techniques to all the images to produce a number of thematic categories (e.g., vegetation classes, water) as described in Yang and Lo (2002). Six spectral bands were used in the classification process that identified, among others, those that were classified as developed within the Atlanta Metropolitan Area, i.e., those areas of high- and low-density urban use.

To calculate fractional vegetation cover $(F r)$ we first calculated the normalized vegetation difference index (NDVI), an index that is commonly used in the remote sensing of vegetation. $N D V I$ is defined as

$$
N D V I=\frac{\rho_{2}-\rho_{1}}{\rho_{2}+\rho_{1}}
$$

where $\rho_{1}$ and $\rho_{2}$ are the measured surface reflectances in the visible red and nearinfrared spectral regions, respectively (wavelength ranges are typically $\rho_{1}=\rho_{\text {red }} \cong \rho_{0.6-0.7 \mu \mathrm{m}}$, $\left.\rho_{2}=\rho_{N I R} \cong \rho_{0.7-1.1 \mu m}\right)$. Clearly, $-1 \leq N D V I \leq 1$, with highly vegetated surfaces characterized by values of $N D V I \approx 0.8$ (this is because, for healthy vegetation, $\rho_{N I R}$ is large and $\rho_{\text {red }}$ is small) and $N D V I \approx 0.1$ for bare soil and impervious surfaces. While the NDVI modulation ratio is correctly defined in terms of surface reflectance, values of which are difficult to ascertain, the use of apparent (i.e., at-sensor) reflectance does not preclude its use in deriving $\mathrm{Fr}$ as demonstrated by Carlson and Ripley (1997). It is therefore only necessary to calculate the apparent reflectance values from the Landsat radiance data using the algorithm provided in the EOSAT technical notes (Markam and Barker, 1986). NDVI calculated thus, is then scaled to an index $N^{* 2}$ (Gillies et al., 1997) which is related to $F r$ as

$$
F r=N^{* 2}
$$

The definition of ISA, as outlined in Carlson and Arthur (2000), is expressed as

$$
I S A=(1-F r)_{d e v}
$$

where the subscript, $d e v$, indicates the quantity is defined only for regions classified as developed, i.e., those areas classified as high- and low-density urban in the Atlanta Metropolitan Region.

ISA was calculated in this way for the all Landsat scenes (1979, 1987 and 1997) using the Imagine ${ }^{\circledR}$ spatial modeler utility. The ISA for the Line Creek watershed (and sub-watersheds) was / were subsequently subset from the scenes using the previously defined AOI(s). A final step 
in the process required using a mask to remove those zero pixels around the AOI(s) such that only those pixels actually within the AOI(s) would be exported to an external ASCII file. This is especially important as zero pixels within the AOI(s) correspond to $F r$ of $100 \%$. The ISA values for each pixel for each year and each watershed were exported as an ASCII file from within Imagine ${ }^{\circledR}$ and were imported into S-Plus (MathSoft, Inc., 2000) Version 5.0 Release 3.0 for Sun SPARC, SunOS 5.5. Within S-Plus, we first removed all pixel values that equaled 0, i.e., that represent $0 \%$ ISA. Then we created histograms and dotplots (Figures 4 and 6) of the non-zero ISA values for each year and each watershed, using uniform scales (when appropriate) to allow for a fast visual comparison of different years and/or different regions. A further plot was produced (Figure 5) indicating percentiles of ISA, including 0\% ISA values. The display and arrangement of mussel species from the different sampling sites (Table 1) has been inspired by color histograms (Wegman, 1990), sometimes also called data images (Minnotte and West, 1998).

\section{Results and Analysis}

Figure 3 shows ISA maps composed using a stream quality classification system as originally proposed by Schueler (1994) and later modified by Arnold and Gibbons (1996). It divides ISA into three groupings that serve as general guidelines for stream quality: less than ten percent (the green zone), ten to twenty-five percent (the yellow zone) and above twenty-five percent (the red zone). Progression from the green towards the red indicates systematic degradation of aquatic habitats from minimal disturbance to severe degradation that may even be irrecoverable. In fact, Booth and Reinelt (1993) concluded that even at ten percent there was "demonstrable and probably irreversible, loss of aquatic system function." Figure 3 indicates a remarkable degree of urbanization within the Line Creek watershed between the years of 1979 and 1997. Furthermore, according to the Soil Conservation Service (1975), ISA in the region of $70 \%$ to $100 \%$ are predominantly industrial, commercial, and shopping center (ICS) complexes while $20 \%$ to $70 \%$ represent residential areas corresponding to lot size - i.e., increases in lot size represent lower ISA. In this context, a spatial trend in urban growth is particularly noticeable in the development of Peachtree City. The level of urbanization here is marked in its growth in ICS complexes and residential development. The bulk of the residential development is observed to be around $40 \%$ to $50 \%$ ISA while there is also some noticeable increase in the region of $20 \%$ to $40 \%$ ISA. According to the Soil Conservations Service (1975) criteria this indicates primarily smaller residential lot size (1/8 to 1/4 acres) but also some larger lot size development (up to 1 acre).

Table 1 shows the increase of pixels classified as developed (and thus resulting in an ISA value) in the MSS and TM images from 1979 to 1997. In 1979, between 15.6\% and 18.0\% of all pixels were classified as developed in the three sub-watersheds. Until 1987, only a minor increase occurred, resulting in $16.5 \%$ to $19.9 \%$ developed pixels. Until 1997, this gap widened, resulting in $29.0 \%$ (Whitewater) to $35.0 \%$ (Line / Flat Creek) developed pixels. Not only are there more pixels classified as developed for Line / Flat Creek than elsewhere in 1997, but the ISA values of pixels are on the higher side. For example, in 1997 the third quartile of all ISA values (where pixels classified as undeveloped have been assigned an ISA value of $0 \%$ ) is $46.0 \%$ for the Line / Flat Creek sub-watershed, 39.8\% for the Line Creek sub-watershed, and 35.4\% for the Whitewater sub-watershed. We will further comment on this later on.

In 1995 all of the sites examined in this study (except P) were visited. Data prior to 1995 were grouped because, although data collected in 1992 were collected quantitatively, we examined only species presence. We made the following assumptions regarding a species 
occurrence: (a) If a species was present during a given visit it was present during all earlier visits, even if it was not observed during some of those earlier visits. (b) A species present at multiple sites had previously been present at all intermediate sites - meaning spatially between sites along a stream course. For example, it is reasonable to assume that Elliptio complanata, observed at all sites except $\mathrm{N}$ in the Line Creek sub-watershed, once was present at site $\mathrm{N}$. (c) If a species was not observed during the last visit to a site it no longer occurred there; however, there is always the possibility that a species was actually present but unobserved.

Table 2 shows mussel species found at different sampling sites. Sites J, K, and L were visited on numerous occasions before 1995. The last visit to each of these sites before 1995 took place in 1992. Some sites were visited after 1995; G, D, and C in 1997 and K and L in 1999. Site P was only visited in 1966 . We use the symbol "+" to indicate that a species was observed at a site in 1995 and later if that site was visited. The symbol "." is used to indicate a species was observed in 1992 or before, but not afterwards (e.g., in 1995). The symbol "-" indicates a species was observed in 1995, but not afterward (i.e., in 1997 or 1999).

Of the fourteen sites visited in this study, six were visited over multiple years. Of those six sites, two (D and C) occur in Whitewater Creek and the rest (G, J, K, and L) reside in Line Creek and further downstream. Two things are apparent when looking at the four sites on Line Creek. (1) Downstream sites historically contained more species than the upstream sites (e.g., K versus J). (2) There was a progression of species loss going from upstream to downstream sites. For example, site $\mathrm{G}$ on Line Creek (well upstream) did not lose any mussel species. Progressing downstream, sites $\mathrm{J}, \mathrm{K}$, and L each lost over $50 \%$ of their mussel species and the loss was progressively greater going downstream. For example, from the 10 species that were present at site J in 1995 or before (i.e., in 1985 and 1992 to be specific), only 5 were observed in 1995 , which relates to a loss of $50 \%$. At site K, $54 \%$ of species disappeared over time. Site L, which historically had the most species of any site, experienced the greatest loss. Eleven of 15 species (73\%) that were initially present at that site had disappeared by 1999 . The species loss at these downstream sites is corroborated with physical changes in these channels observed between the mid 1960's and 1995. For example, both sites K and L have undergone channel widening and marked instability (J. Brim Box, unpublished data). These changes are consistent with streams heavily impacted by urbanization.

Two of the six sites surveyed over multiple years occurred in the Whitewater Creek subwatershed. Species losses at those sites were less than those on Line Creek. For example, site C lost no mussel species between 1995 and 1997 and site D lost 30\%. It is possible that species losses at Site D were due, in part, to the reservoir directly above that site. Declines in mussel species below dams in other drainages have been well documented (e.g., Williams et al., 1992; Bates, 1962).

The histograms (Figure 4) and percentiles (Figure 5) show the increase of pixels with ISA values greater than $0 \%$ for the watersheds for the years 1979, 1987, and 1997. It should be noted that the 1979 data are based on an MSS image while the data for 1987 and 1997 are based on TM images that contain approximately four times as many pixels per unit area as MSS images. In 1979, no major differences were noted in the distribution of ISA pixel values for the three subwatersheds, based upon both histograms and percentiles (Figures 4 and 5). These figures show a much larger spread of ISA in 1987 and 1997 than in 1979. This can be partially explained by the higher resolution of TM compared to MSS images. If we assume that we are looking at a region where no change has taken place from 1979 to 1987 and this region represents an ICS pixel in MSS, a breakdown of this pixel would lead to about four ICS pixels in TM (at least theoretically when the pixels are lined-up exactly). Otherwise, if there is one TM pixel with a relatively small 
ISA value in 1987 (and this pixel is defined as developed) and three neighboring TM pixels that are not classified as developed, an aggregation would most likely result in an MSS pixel that is not classified as developed, thus eliminating small ISA values for MSS pixels.

Another explanation is needed why there are no ISA values below 50\% in 1979: Residential areas mostly consisted of small lot sizes, with many buildings falling into a single MSS pixel. With an increase in lot size, only a few of these buildings would fall into a TM pixel, thus resulting in a lower ISA value.

The underlying data, summarized in Table 1, show that in 1979, only $16.7 \%$ of all pixels had an ISA value greater than 0\%. In 1987 and 1997, 17.7\% and 30.9\%, respectively, of all pixels had an ISA value greater than 0\%. The increase in non-zero pixels from 1979 to 1987 took place over the entire range of ISA values, representing the growth of ICS complexes as well as residential areas. However, differences among the sub-watersheds are visible. The combined Line Creek / Flat Creek sub-watersheds show the highest increase in high ISA values related to ICS complexes. Although ISA increases across sub-watersheds between 1987 and 1997 took place, the type of development that these ISA values represent were different. While all sub-watersheds show a considerable increase in lower ISA values related to residential areas, the combined Line / Flat Creek sub-watershed and the Line Creek sub-watershed had the largest increase in high ISA values related to ICS complexes. For Whitewater, there was no observable increase in high ISA values related to ICS complexes from 1987 to 1997.

Figure 5 shows percentiles $\left(85^{\text {th }}\right.$ to $100^{\text {th }}$ for 1979 and 1987 , and $70^{\text {th }}$ to $100^{\text {th }}$ in 1997 ; in steps of 5) of ISA percentage, based on all pixels. This needs some additional explanation. While one would typically expect boxplots to compare characteristics of different distributions, boxplots are quite useless here. In 1979 for example, less than $20 \%$ of the pixels were classified as developed. In a boxplot (not shown) for this year, the first quartile (i.e., $25^{\text {th }}$ percentile), median, and third quartile (i.e., $75^{\text {th }}$ percentile) are all 0 , leaving only the upper tail visible. Instead, we present a breakdown of this tail, displaying only the high percentiles that relate to ISA percentages greater than 0 . For this display, we make the assumption that pixels classified as nondeveloped have an ISA value of 0. From Figure 5 we can see that in 1979, for example, the highest $5 \%$ of the ISA values were all in the range from around $84 \%$ to $100 \%$ for all subwatersheds. In 1987, the highest 5\% of the ISA values were in the range $79 \%$ to $100 \%$ for the Whitewater sub-watershed and $84 \%$ to $100 \%$ for the Line / Flat Creek sub-watershed. The percentiles for 1997 suggest an increase of low ISA values for all sub-watersheds. In addition, the Whitewater sub-watershed has far less than $10 \%$ of its ISA values above $70 \%$ (in fact, the highest $10 \%$ of the ISA values are in the range $63 \%$ to $100 \%$ ). For the Line Creek sub-watershed and the Line / Flat Creek sub-watersheds, the highest $10 \%$ of the ISA values are above $68 \%$ and $71 \%$, respectively, indicating a considerably higher percentage of ICS complexes for the latter subwatersheds than for Whitewater.

Figure 6 complements Figures 4 and 5,showing the increase / decrease from 1987 to 1997 in the number of pixels for each 5\% ISA interval. All four plots, representing the different subwatersheds and the entire watershed, indicate a major increase in ISA values that relate to residential areas, i.e., ISA values in the range from $20 \%$ to $70 \%$. The Line Creek sub-watershed has a noticeable increase for the ICS complexes ISA values as well, in particular on the high-end from $95 \%$ to $100 \%$. The combined Line / Flat creek sub-watershed shows an additional increase for the ICS complexes ISA values in the range from $70 \%$ to $80 \%$, however no additional increase takes place on the high-end side from $95 \%$ to $100 \%$. For the Whitewater Creek sub-watershed, no major increase for the ICS complexes ISA values in the range from $70 \%$ to $100 \%$ takes place. 
Obviously, an increase in ISA values takes place on pixels that previously were nonurban and have become urbanized. In addition, a small decrease in average / high pixels (from $80 \%$ to 95\%) has been observed for Line Creek and the combined Line / Flat Creek subwatersheds. This could mean that for some pixels previously classified as ICS pixels even more construction took place, shifting these pixels into the $95 \%$ to $100 \%$ ISA class. Also some measurement error / adjustment error could explain part of the decrease in some of the classes.

Note that a difference plot, as shown in Figure 6, is not reasonable for the years 1979 to 1987 since the 1979 data is from the MSS sensor which has a lower resolution than the 1987 / 1997 data from a TM sensor. As explained earlier, some pixels classified as residential in 1987 / 1997 would have been classified as non-residential in 1979, thus resulting in an artificial loss of pixels with small ISA values in 1979. In addition, the total number of pixek for 1979 and 1987 / 1997 is different. While the histograms in Figure 4 provide a good graphical summary of the underlying data, the conversion of pixel counts into percentages and the subsequent construction of a difference plot based on percentages might be considered unreliable. The problem that is caused by aggregating geo-referenced data at different spatial resolutions is known as the modifiable areal unit problem, introduced in Openshaw and Taylor (1979) and further discussed in Wong (1996).

\section{Discussion and Conclusions}

An interesting phenomenon was noticed between years 1979 and 1987. In both years the number of pixels with an ISA greater than zero are about the same $(16.7 \%$ and $17.7 \%)$. There are two possible reasons for this: a spatial resolution issue between MSS (56 metres) and TM (30 metres). In 1979 a pixel classified urban may only have been partially covered with buildings and roads, whereas in 1987 it would be broken into several pixels, representing both urban and nonurban areas, and leading to a decrease in the percentage of urban pixels, or between 1979 and 1987 areas being developed in 1979 would mature (in terms of vegetation coverage) by 1987 which could lead to a reduction in ISA pixels. So based upon this possible reduction one might conclude there is some effective increase in ISA pixels from 1979 to 1987.

Reference to Figure 3 reveals the degree of urban development over the entire watershed. This development is particularly visible between the years 1987 and 1997. Changes in ISA in the watershed occurred predominantly at the high end, that is, moving into the red zone diagramed by Arnold and Gibbons (1996). Ecological impacts of this type of shift in ISA would probably be noted in the watershed, as suggested by Schueler (1994). Empirical evidence, in terms of aquatic species richness, was available to assess the relative impact of changes in ISA in the Line Creek and Whitewater watersheds and, further downstream Line Creek to below the confluence of Line Creek and Flat Creek.

Downstream after the Line / Flat Creek confluence it was observed that sites K and L (ref., Figure 1) lost 54\% and 73\% of their mussel species, respectively. On Whitewater Creek, where the overall development of ISA was less, site C lost no species and site D lost 30\%. Site D was unusual, however, in that a dam immediately upstream may have contributed to species loss.

As Figure 3 shows, the increase in ISA upstream on the Line Creek sub-watershed was minimal as compared to downstream sites. Upstream sites $\mathrm{H}$ and $\mathrm{G}$ had no major mussel species losses. However, it was noticeable that for sites $\mathrm{J}$ and $\mathrm{K}$ further downstream on Line Creek significant (i.e., over 50\%) species losses occurred during the study period. Reference to Figure 3 
corroborates a significant drainage from Peachtree City into these sites that could have resulted in the concomitant species loss and changes in streambed morphology observed.

The urbanization of the entire watershed is the most widespread human activity that could potentially impact freshwater mussels. Negative impacts could result from both changes in sediment production and channel instability. Increases in ISA reduce infiltration rates, leading to an increase in the frequency and magnitude of flooding, and an increase in runoff volume for a given rain event (Arnold et al., 1982; Morisawa and LaFlure, 1979). In addition, ISA reduces sediment supplied from the surrounding watershed, and eventually urbanization can lead to bank erosion and bed scouring (Trimble, 1997). Both of these physical changes to Line Creek's channel were documented at site K (J. Mossa, University of Florida, pers. comm.), which lost over $50 \%$ of its historical mussel fauna.

We certainly do not want to claim that an increase in ISA "causes" the loss of mussel species. However, as shown in this paper, ISA (an aggregate of many factors, some of which may "cause" the loss of species) is a good indicator that is "associated" with the loss of mussel species. Obtaining ISA percentages (based on remotely sensed data) for larger regions than in this study may quickly focus urban planners and environmentalists to regions where aquatic species are severely endangered - and to implement corrective actions that prevent future habitat degradation and aquatic species losses.

\section{Acknowledgements}

The authors would like to acknowledge the work done by Dr. C.P. Lo and Xiaojun Yang who classified the images as part of research funded by the National Aeronautics and Space Administration (NASA) through a grant/contract \#NAS8-97081. We would like to thank Brad Barfuss, an undergraduate in Geography in the department of Geography and Earth Resources at Utah State University, who helped with the calibration of the Landsat data. The participation by Robert R. Gillies was supported in part by the Utah Agricultural Experiment Station, Utah State University, Logan, Utah and by NASA through a grant/contract \#NAG8-1750. We are very much indebted to the reviewers as their comments helped clarify many aspects of this interdisciplinary paper. 


\section{References}

Allan, J. and A. Flecker, 1993. Biodiversity conservation in running waters: Identifying the major factors that threaten destruction of riverine species and ecosystems. BioScience, 43: 32-43.

Arnold, C. L. and C. J. Gibbons, 1996. Impervious surface coverage: the emergence of a key environmental indicator. Journal of the American Planning Association, 62 (2): 243-258.

Arnold, C. L., P. J. Boison, and P. C. Patton. 1982. Sawmill Brook: an example of rapid geomorphic change related to urbanization. Journal of Geology, 90: 155-166.

Bates, J. M. 1962. The impact of impoundments on the mussel fauna of Kentucky Reservoir, Tennessee River. American Midland Naturalist, 68: 232-236.

Bogan, A. E., 1993. Freshwater bivalve extinctions (Mollusca:Unionoida): A search for causes. American Zoologist, 33: 599-609.

Booth, D. B., 1990. Stream-channel incision following drainage-basin urbanization. American Resources Bulletin, 26 (3): 407-417.

Booth, D. B. and L. E. Reinelt, 1993. Consequences of urbanization on aquatic systems measured effects, degradation thresholds, and corrective strategies. Proceedings: Watershed '93: A National Conference on Watershed Management, March 21-24, Alexandria, Virginia, pp. 545-550.

Brim Box, J. and J. Mossa, 1999. Sediment, land use and freshwater mussels: prospects and problems. Journal of the North American Benthological Society, 18: 99-117.

Brim Box, J. and J. D. Williams, 2000. Unionid mollusks of the Apalachicola Basin in Alabama, Florida and Georgia. Bulletin of the Alabama Museum of Natural History, 21: 1-143.

Butler, R., 1993. Results of a status survey for eight freshwater mussels (Bivalvia: Unionidae) endemic to eastern Gulf slope drainages of the Apalachicolan region of southeast Alabama, southwest Georgia, and north Florida. U.S. Fish and Wildlife Service, Jacksonville, Florida.

Carlson, T. N. and D. A. J. Ripley, 1997. On the relationship between NDVI, fractional vegetation cover and leaf area index. Remote Sensing of Environment, 61: 241-252.

Carlson, T. N. and S. T. Arthur, 2000. The impact of land use - land cover changes due to urbanization on surface microclimate and hydrology: a satellite perspective. Global and Planetary Change, 25: 49-65.

Fontaine, T. D. and S. M. Bartell (editors), 1983. Dynamics of Lotic Ecosystems. Ann Arbor Science Publishers, Ann Arbor.

Fuller, S. L. H., 1974. Clams and mussels. Pages 215-273 in C. W. Hart and S. L. H. Fuller (editors). Pollution ecology of freshwater invertebrates. Academic Press, New York. 
Gillies, R. R., T. N. Carlson, J. Cui, W. P. Kustas, and K. S. Humes, 1997. A verification of the 'triangle' method for obtaining surface soil water content and energy fluxes of the Normalized Difference Vegetation Index (NDVI) and surface radiant temperature. International Journal of Remote Sensing, 18: 3145-3166.

Hammer, T. R., 1972. Stream channel enlargement due to urbanization. Water Resources Research, 8 (6): 1530-1540.

Harris, L. D. and J. G. Gosselink, 1990. Cumulative impacts of bottomland hardwood forest conversions on hydrology, water quality, and terrestrial wildlife. Pages 259-324 in J. G. Gosselink, L. C. Lee, and T. A. Muir (editors). Ecological Processes and Cumulative Impacts: Illustrated by Bottomland Hardwood Wetland Ecosystems. Lewis Publishers, Chelseas, Michigan.

Hollis, G. E., 1975. The effect of urbanization on floods of different recurrence interval. Water Resources Research, 11 (3): 431-435.

Hunsaker, C. T. and D. A. Levine, 1995. Hierarchical approaches to the study of water quality in rivers. Bioscience, 45 (3): 183-192.

Jackson, T. J. and R. H. McCuen, 1979. Accuracy of impervious surface area values estimated using remotely sensed data. Water Resources Bulletin, 15 (2): 436-446.

Jennings, D. and S. T. Jarnagin, 2000. Impervious surfaces and streamflow discharge: a historical remote sensing perspective in a northern Virginia subwatershed. ASPRS Annual Conference Proceedings, Washington, D.C. May 22-26, 2000. CD-ROM.

Klein, R. D., 1979: Urbanization and stream water quality impairment. Water Resources Bulletin, 15 (4): 948-963.

Leopold, L. B., 1973: River channel change with time: an example. Geological Society of America Bulletin, 84: 1845-1860.

Ligon, F. K., W. E. Dietrich, and W. J. Trush, 1995. Downstream ecological effects of dams: a geomorphic perspective. BioScience, 45: 183-192.

Markam, B. L. and J. L. Barker, 1986. Landsat MSS and TM post-calibration dynamic ranges, exoatmospheric reflectances and at-satellite temperatures. EOSAT Landsat Tech. Note, 1: 38.

Minnotte, M. C. and R. W. West, 1998. The data image: A tool for exploring high dimensional data sets, 1998 Proceedings of the Section on Statistical Graphics, American Statistical Association, Alexandria, Virginia, 25-33.

Morisawa, M. and E. LaFlure, 1979. Hydraulic geometry, stream equilibrium, and urbanization. Pages 333-350 in D. D. Rhodes and G. P. Williams (editors). Adjustments of the fluvial system. Kendall/Hunt, Dubuque, Iowa.

Nature Conservancy, 1996. Priorities for Conservation: 1996 Annual Report Card for U.S. Plant and AnimalSpecies. The Nature Conservancy, Washington, D.C. 
Neves, R. J., A. E. Bogan, J. D. Williams, S. A. Ahlstedt, and P. W. Hartfield, 1997. Status of aquatic mollusks in the southeastern United States: a downward spiral of diversity. Pages 4486 in G. W. Benz and D. E. Collins (editors). Aquatic fauna in peril: the southeastern perspective. Special Publication 1, Southeast Aquatic Research Institute. Lenz Design and Communications, Decatur, Georgia.

Newbury, R. W., 1984. Hydrological determinants of aquatic insect habitats. Pages 323-357 in V. H. Resh and D. M. Rosenberg (editors). The Ecology of Aquatic Insects, Praeger, New York.

Nott, M. P., E. Rogers, and S. Pimm, 1995. Modern extinctions in the kilo-death range. Current Biology, 5: 14-17.

Openshaw, S. and P. J. Taylor, 1979. A million or so correlation coefficients: three experiments on the modifiable areal unit problem. Pages 127-144 in N. Wrigley (editor). Statistical Applications in the Spatial Sciences. Pion Limited, London.

Ridd, M. K., 1995. Exploring a V-I-S (vegetation-impervious surface-soil) model for urban ecosystems analysis through remote sensing: comparative anatomy for cities. International Journal of Remote Sensing, 16 (12): 2165-2185.

Schueler, T., 1994. The importance of imperviousness. Watershed Protection Techniques, 1 (3): 100-111.

SCS (Soil Conservation Service), 1975. Urban Hydrology for Small Watersheds. USDA, SCS Technical Release No. 55, Washington D.C.

Strayer, D. 1983. The effects of surface geology and stream size on freshwater mussel (Bivalvia, Unionidae) distribution in southeastern Michgan, USA. Freshwater Biology, 13: 253-264.

Strayer, D. L., S. Claypool, and S. J. Sprague, 1997. Assessing unionid population with quadrats and timed searches. Pages 163-169 in K. S. Cummings, A. C. Buchanan, C. A. Mayer, and T. J. Naimo (editors). Conservation and management of freshwater mussels II: initiatives for the future. Upper Mississippi River Conservation Committee, Rock Island, Illinois.

Todd, D. A., P. B. Bedient, J. F. Haasbeek, and J. Noell, 1989. Impact of land use and NPS load on lake Quality. Journal of Environmental Engineering, 115 (3): 633-649.

Trimble, S. W., 1997. Contribution of stream channel erosion to sediment yield from an urbanizing watershed. Science, 214: 1442-1444.

U.S. Census Bureau, 2000. (SU-99-7) Population Estimates for Places (Sorted Alphabetically Within State): Annual Time Series, July 1, 1990 to July 1, 1999. Population Estimates Program, Population Division, U.S. Census Bureau, Washington, D.C.

Web: http://eire.census.gov/popest/archives/place/placebyst/SC99T7_GA.txt.

Vaughn, C. C., C. M. Taylor, and K. J. Eberhard, 1997. A comparison of the effectiveness of timed searches vs. quadrat samples in mussel surveys. Pages 157-162 in K. S. Cummings, A. C. Buchanan, C. A. Mayer, and T. J. Naimo (editors). Conservation and management of freshwater mussels II: initiatives for the future. Upper Mississippi River Conservation Committee, Rock Island, Illinois. 
Wegman, E. J., 1990. Hyperdimensional data analys is using parallel coordinates. Journal of the American Statistical Association, 85: 664-675.

Williams, J. D., S. L. H. Fuller, and R. Grace, 1992. Effects of impoundments on freshwater mussels (Mollusca: Bivalvia: Unionidae) in the main channel of the Black Warrior and Tombigbee Rivers in western Alabama. Bulletin Alabama Museum of Natural History, 13: 110.

Williams, J. D., M. Warren, K. Cummings, J. Harris, and R. Neves, 1993. Conservation status of freshwater mussels of the United States and Canada. Fisheries, 18: 6-22.

Williams, J. D. and R. J. Neves, 1995. Freshwater mussels: A neglected and declining aquatic resource. Pages 19-21 in E. T. LaRoe, G. S. Farris, C. E. Puckett, P. D. Doran, and M. J. Mac (editors). Our living resources: a report to the nation on the distribution, abundance, and health of U.S. plants, animals, and ecosystems. U. S. Department of the Interior, National Biological Service, Washington, DC.

Wong, D., 1996. Aggregation effects in geo-referenced data. Pages 83-106 in S. L. Arlinghaus (editor). Practical Handbook of Spatial Statistics. CRC Press, Boca Raton, Florida.

Yang, X. and C. P. Lo, 2002. Using a time series of satellite imagery to detect land use and land cover changes in the Atlanta, Georgia Metropolitan area. International Journal of Remote Sensing, 23 (9): 1775-1798. 


\section{Tables Captions}

Table 1. The percentage of non-zero pixels (i.e., those containing some impervious surface area) in the entire watershed of Line Creek (LFW) and, in the sub-watersheds of Line Creek, Line / Flat and Whitewater creeks.

Table 2. Sites versus Species versus Year (body) for the Line Creek / Flat Creek / Whitewater sampling sites near Atlanta, GA. The status indicates how critical the condition of a species is in general $(\mathrm{cs}=$ currently stable, $\mathrm{sc}=$ special concern, $\mathrm{e}=$ endangered, $\mathrm{t}=$ threatened, $\mathrm{x}=$ extinct) . The top row shows sites, labeled according to Figure 1, and the first column shows mussel species. Sites have been arranged from upstream to downstream location. Watersheds are separated by an additional space. Mussel species have been arranged in such a way that species that have been observed at similar sites are listed close to each other. 


\section{Figure Captions}

Figure 1. Site map showing study sites (A through L) on the Line and Whitewater creeks, near Atlanta, Georgia. Sites O, further downstream, and P, to the east of Peachtree City, are located outside this map.

Figure 2. The delineated watersheds of (a) Line Creek, (b) Line / Flat Creek, (c) Whitewater Creek, and (d) the entire drainage area (LFW). The gradation in grey is associated with degree of ISA.

Figure 3. ISA ( 0 to 1 representing 0 to $100 \%$ ) maps for the entire Watershed (LFW) for the years 1979, 1987, and 1997. Color coding represents the degree of ecological impact, as outlined by Schueler (1994).

Figure 4. Histograms showing ISA values (0 to 1 representing 0 to $100 \%$ ) for the different watersheds (delineated pictorially on top as Line, Line / Flat, Whitewater creeks, and the entire drainage area representing Line Creek (LFW)) for the years 1979, 1987, and 1997. Axes are, vertical - number of pixels (sensor) versus Percentage of ISA (horizontal).

Figure 5. Percentiles of ISA percentages ( 0 to 1 representing 0 to 100\%), based on all pixels, for the different watersheds (Line, Line / Flat, Whitewater creeks, and the entire drainage area representing Line Creek (LFW)) for the years 1979, 1987, and 1997.

Figure 6. Dotplots indicating differences in number of ISA pixels from 1987 to 1997 for the different watersheds (Line, Line / Flat, Whitewater creeks, and the entire drainage area (LFW)). Differences were calculated for intervals of ISA percentages ( 0 to 1 representing 0 to 100\%) of width $5 \%$, e.g., the value plotted at 1.0 relates to the $95 \%$ to $100 \%$ interval of ISA percentages. 


\begin{tabular}{|ll|l|l|}
\hline & \multicolumn{3}{|c|}{ Year } \\
\cline { 4 - 4 } & \multicolumn{3}{|c|}{} \\
Watershed & 1979 & 1987 & 1997 \\
\cline { 1 - 1 } LFW & 16.7 & 17.7 & 30.9 \\
Line Creek & 15.6 & 16.5 & 30.9 \\
Line/Flat & 16.3 & 19.9 & 35.0 \\
Whitewater & 18.0 & 17.2 & 29.0 \\
& & & \\
Table 1. The percentage of non-zero pixels \\
(i.e., those containing some impervious surface \\
area) in the entire watershed of Line Creek \\
(LFW) and, in the sub-watersheds of Line \\
Creek, Line / Flat and Whitewater creeks. \\
\hline
\end{tabular}




\begin{tabular}{|c|c|c|c|c|c|c|c|c|c|c|c|c|c|c|c|}
\hline \multirow[b]{3}{*}{ Species } & \multicolumn{14}{|c|}{ SITE LOCATION } & \multirow[b]{3}{*}{ Status } \\
\hline & \multicolumn{5}{|c|}{ Line Creek } & \multicolumn{2}{|c|}{$\mathbf{L} / \mathbf{F}$} & \multicolumn{4}{|c|}{ Whitewater } & \multicolumn{3}{|c|}{ Other ${ }^{*}$} & \\
\hline & H G. & $\mathbf{J} \quad \mathbf{A}$ & B & $\mathbf{N}$ & $\mathbf{E}$ & $\mathbf{F}$ & $\mathbf{K}$ & I & $\mathbf{M}$ & D & C & $\mathbf{L}$ & $\mathbf{O}$ & $\mathbf{P}$ & \\
\hline Elliptio complanata & ++ & + & + & & + & + & + & + & + & + & + & & + & & $\mathrm{cs}$ \\
\hline Villosa vibex & ++ & $+\quad+$ & + & + & & & + & & & - & + & - & & & cs \\
\hline Toxolasma paulus & ++ & - + & + & & & & - & + & & + & + & - & & & $\mathrm{cs}$ \\
\hline Villosa lienosa & ++ & - + & & & & & - & + & & + & + & - & & & $\mathrm{cs}$ \\
\hline Quincuncina infucata & + & $+\quad+$ & + & & & & + & + & + & - & + & - & + & & $\mathrm{sc}$ \\
\hline Megalonaias nervosa & & & & + & + & & + & & & + & + & + & + & \# & cs \\
\hline Utterbackia mbecillus & & + & & & & & - & & & & & - & & & $\mathrm{cs}$ \\
\hline Pyganodon grandis & & + & & & & & - & & & + & & & & & $\mathrm{cs}$ \\
\hline Lampsilis subangulata & & - & & & & & + & & & & + & + & & \# & $\mathrm{e}$ \\
\hline Elliptio icterina & & - & & & & & + & & & & & + & & & cs \\
\hline Elliptio arctata & & - & & & & & - & & & & & - & & & $\mathrm{sc}$ \\
\hline Lampsilis claibornensis & & & & & & & $\bullet$ & & & & & & & & sc \\
\hline Villosa villosa & & & & & & & - & & & & & & & & $\mathrm{sc}$ \\
\hline Uniomerus caroliniana & & & + & & & & & & & & & & & & cs \\
\hline Anodontoides radiatus & & & & & & & & & & & & - & & \# & $\mathrm{e}$ \\
\hline Alasmidonta triangulata & & & & & & & & & & & & - & & \# & $\mathrm{e}$ \\
\hline Medionidus penicillatus & & & & & & & & & & & + & $\bullet$ & & & e \\
\hline Lampsilis binominata & & & & & & & & & & & & $\bullet$ & & & $\mathrm{x}$ \\
\hline Elliptoideus sloatianus & & & & & & & & & & & & $\bullet$ & & & $\mathrm{t}$ \\
\hline Elliptio crassidens & & & & & & & & & & + & & & & & cs \\
\hline Utterbackia peggyae & & & & & & & & & & + & & & & & $\mathrm{cs}$ \\
\hline Lampsilis teres & & & & & & & & & & - & & & & & cs \\
\hline \multicolumn{16}{|l|}{ Key: } \\
\hline \multirow{2}{*}{\multicolumn{16}{|c|}{$\begin{array}{l}-\quad \text { Observed in } 1992 \text { or before, but not afterwards. } \\
+\quad \text { Observed in } 1995 \text { and later if that site was visited. }\end{array}$}} \\
\hline & & & & & & & & & & & & & & & \\
\hline \multicolumn{16}{|c|}{ Observed in 1995, but not afterwards (G, D \& C: 1997; K \& L: 1999). } \\
\hline \multicolumn{16}{|c|}{ Historic data from 1966, no later visits to this site. } \\
\hline \multicolumn{16}{|c|}{$\begin{array}{l}\mathrm{L} / \mathrm{F} \text { Sampling sites with feeds from Line and Flat creeks. } \\
{ }^{*} \text { Site L is on Line Creek (with feeds from Flat and Whitewater creeks) while Sites O and P are situated on } \\
\text { the Flint River. }\end{array}$} \\
\hline \multicolumn{16}{|c|}{$\begin{array}{l}\text { Table 2. Sites versus Species versus Year (body) for the Line Creek / Flat Creek / Whitewater } \\
\text { sampling sites near Atlanta, GA. The status indicates how critical the condition of a species is in } \\
\text { general ( } \mathrm{cs}=\text { currently stable, } \mathrm{sc}=\text { special concern, } \mathrm{e}=\text { endangered, } \mathrm{t}=\text { threatened, } \mathrm{x}=\text { extinct). The } \\
\text { top row shows sites, labeled according to Figure } 1 \text {, and the first column shows mussel species. Sites } \\
\text { have been arranged from upstream to downstream location. Watersheds are separated by an } \\
\text { additional space. Mussel species have been arranged in such a way that species that have been }\end{array}$} \\
\hline
\end{tabular}




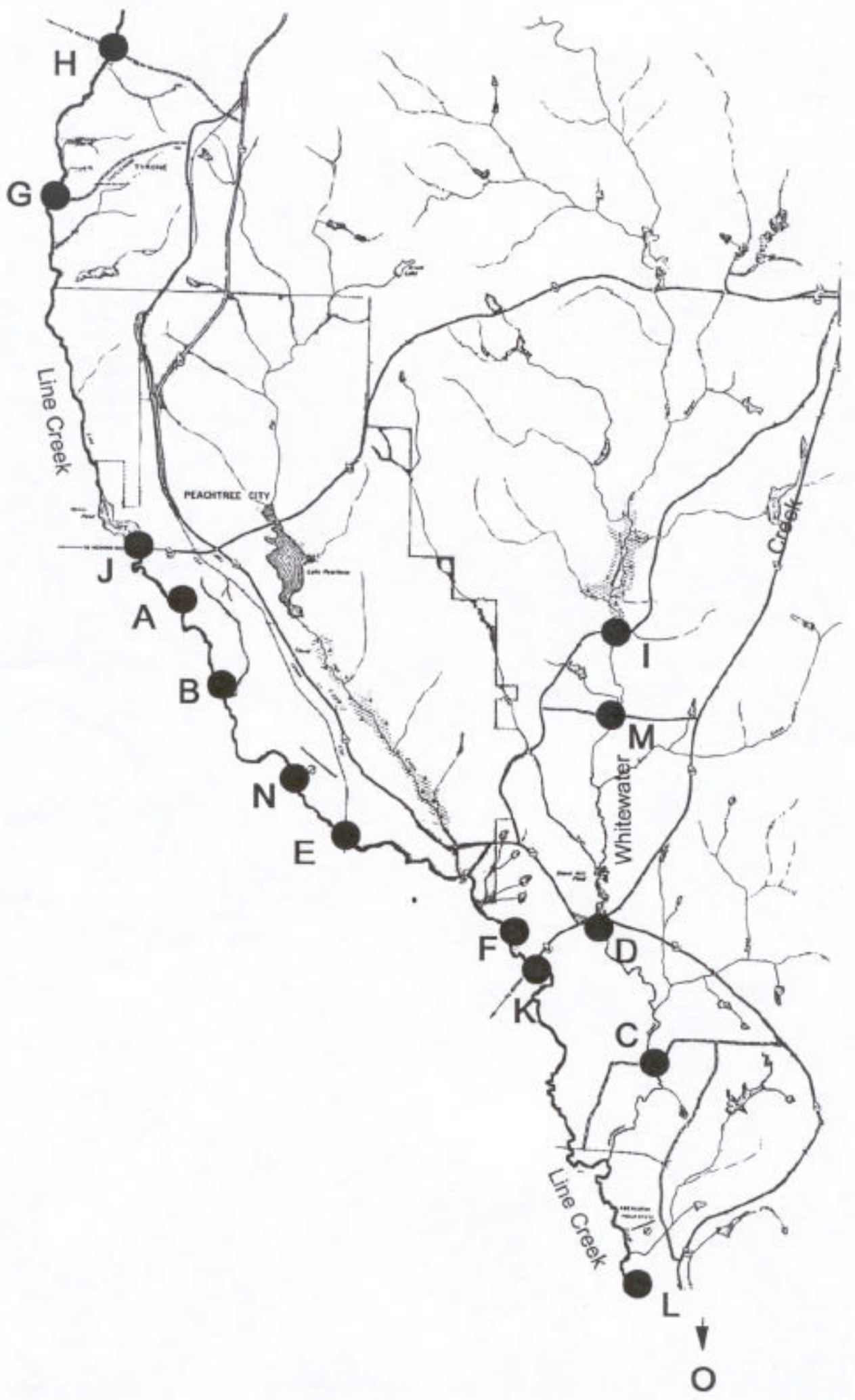

Figure 1. Site map showing study sites (A through L) on the Line and Whitewater creeks, near Atlanta, Georgia. Sites O, further downstream, and P, to the east of Peachtree City, are located outside this map. 


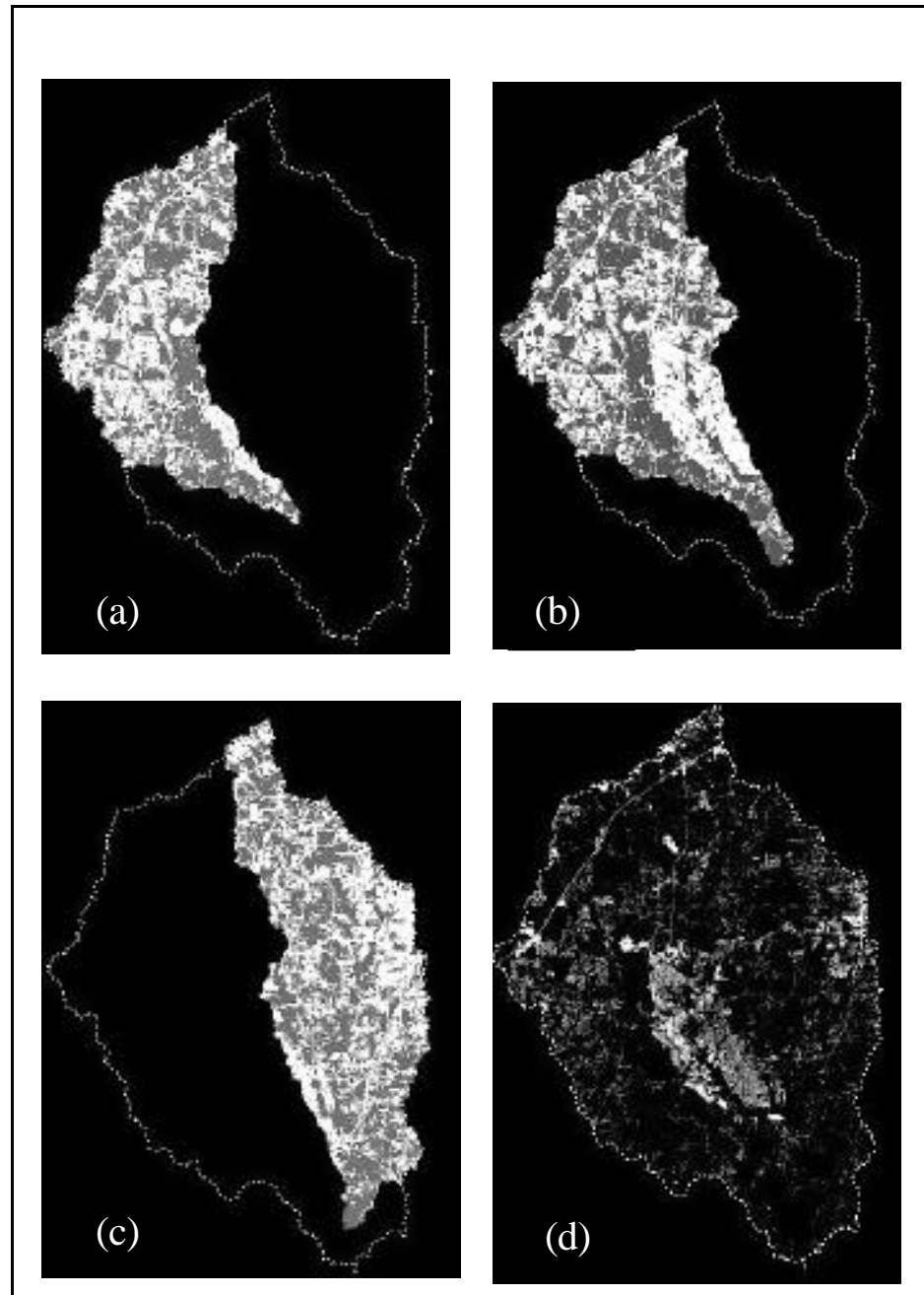

Figure 2. The delineated watersheds of (a) Line Creek, (b) Line / Flat Creek, (c) Whitewater Creek, and (d) the entire drainage area (LFW). The gradation in grey is associated with degree of ISA. 


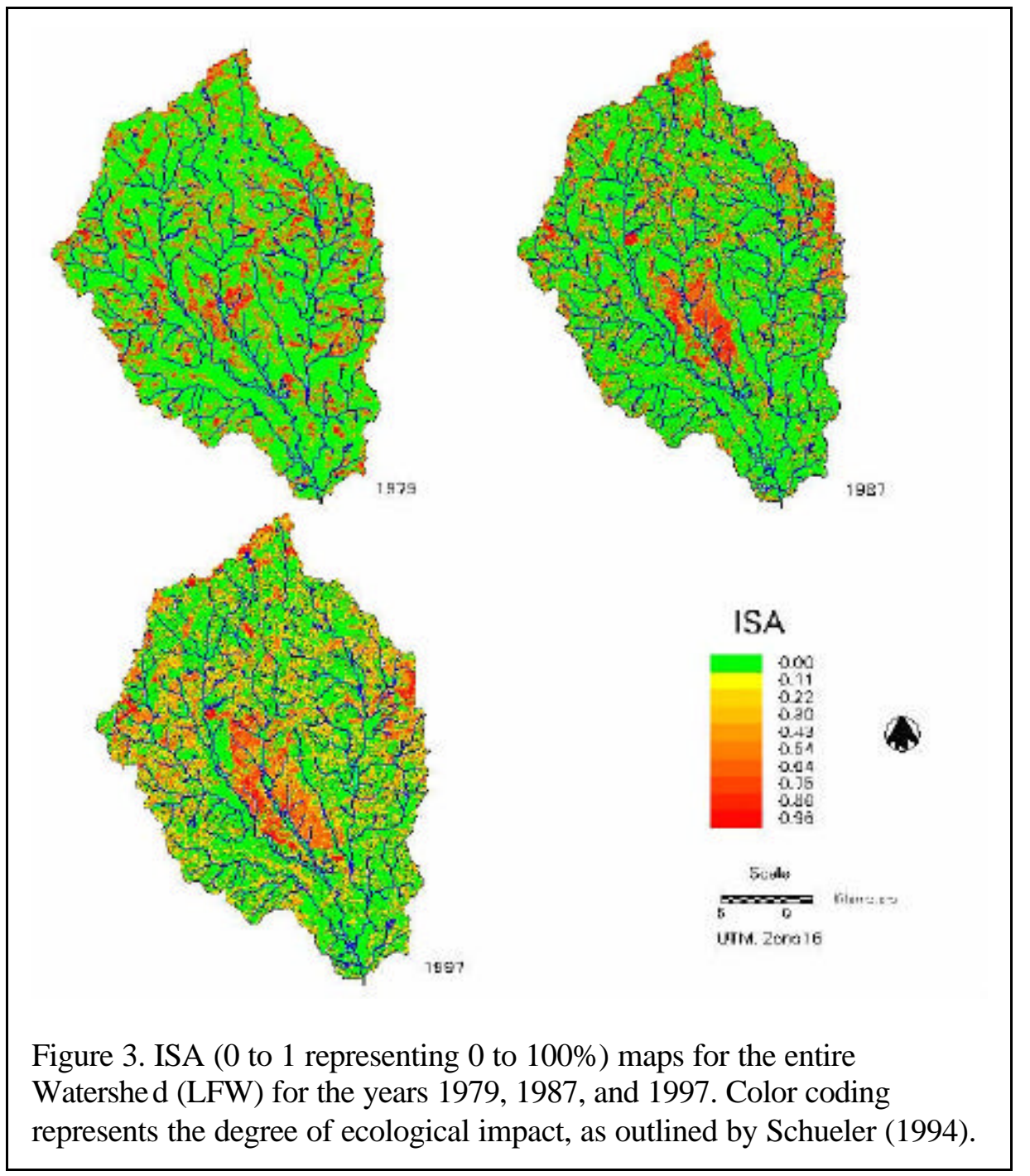




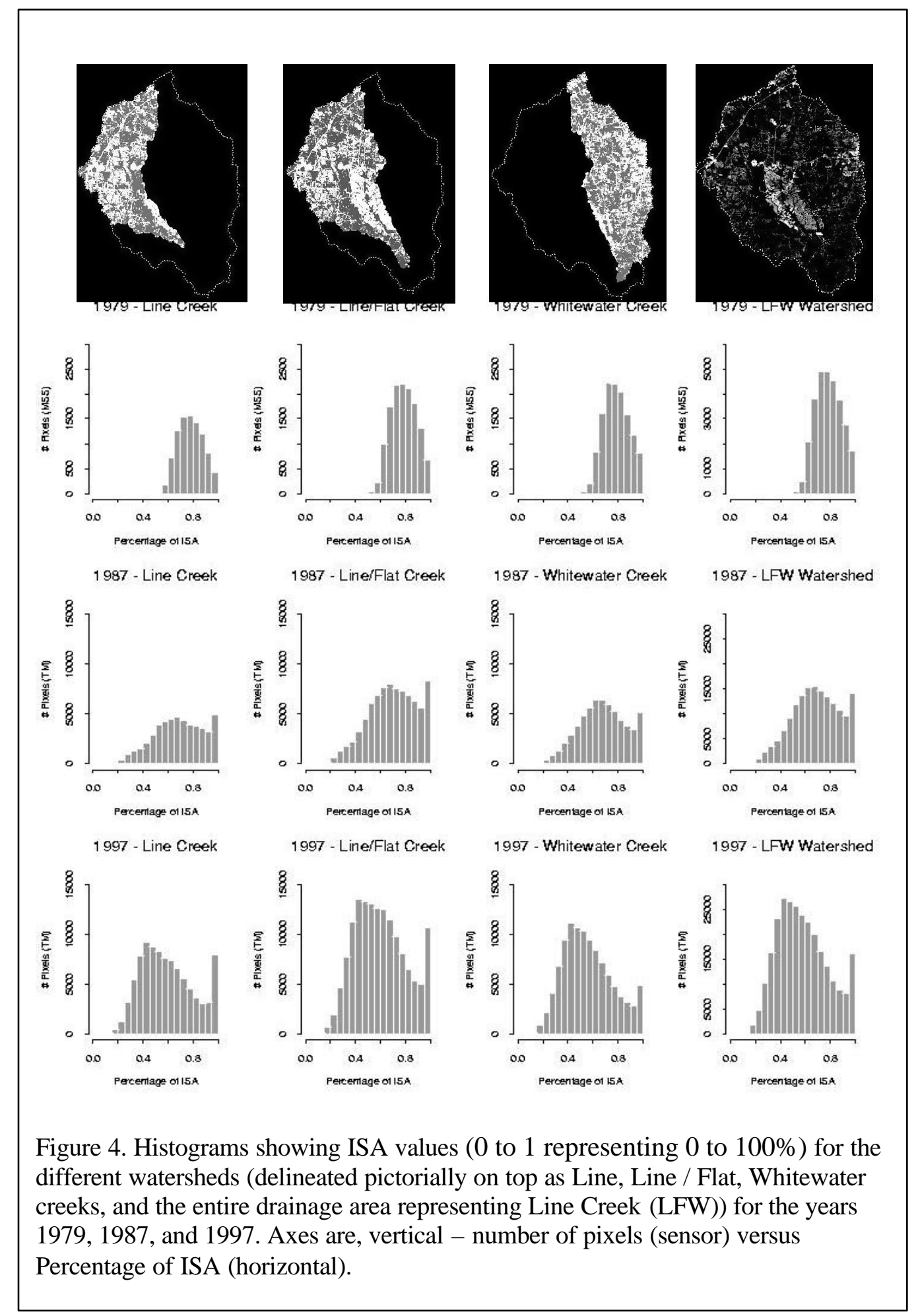




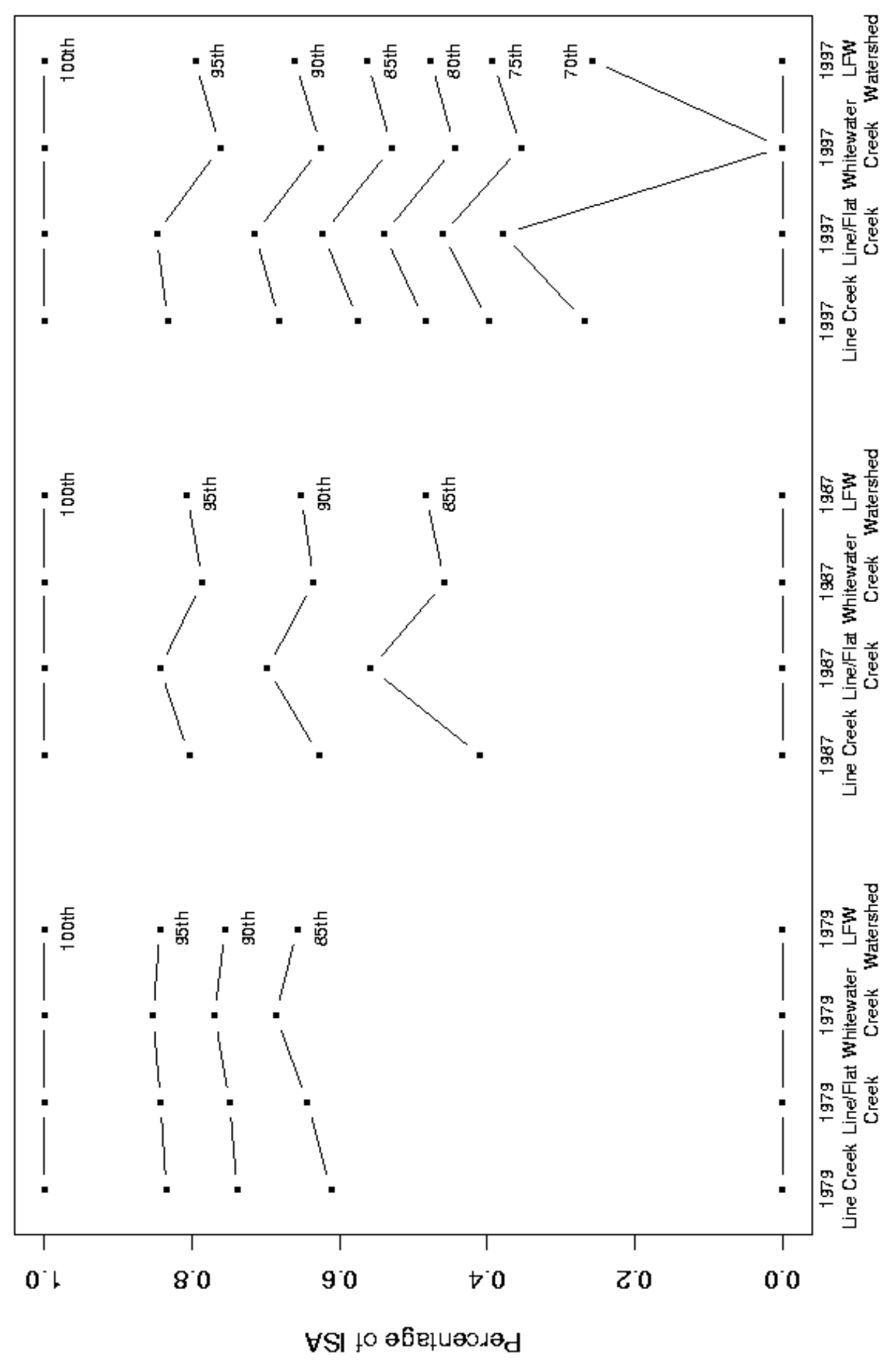

Figure 5. Percentiles of ISA percentages ( 0 to 1 representing 0 to $100 \%$ ), based on all pixels, for the different watersheds (Line, Line / Flat, Whitewater creeks, and the entire drainage area representing Line Creek (LFW)) for the years 1979, 1987, and 1997. 


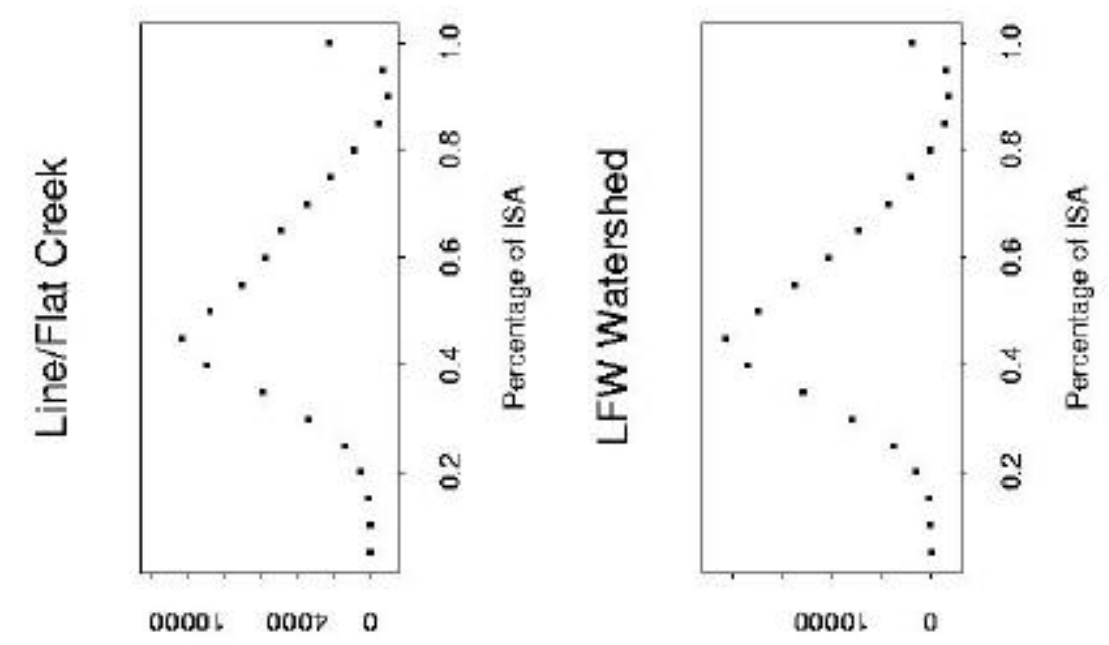

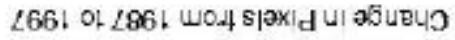

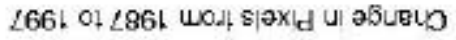

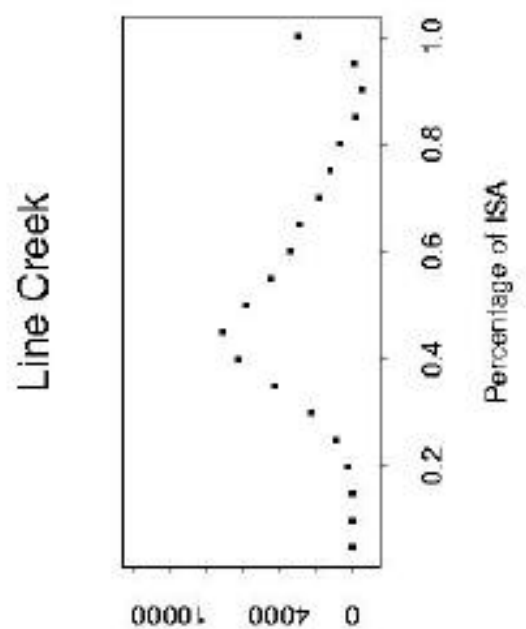

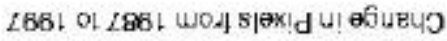

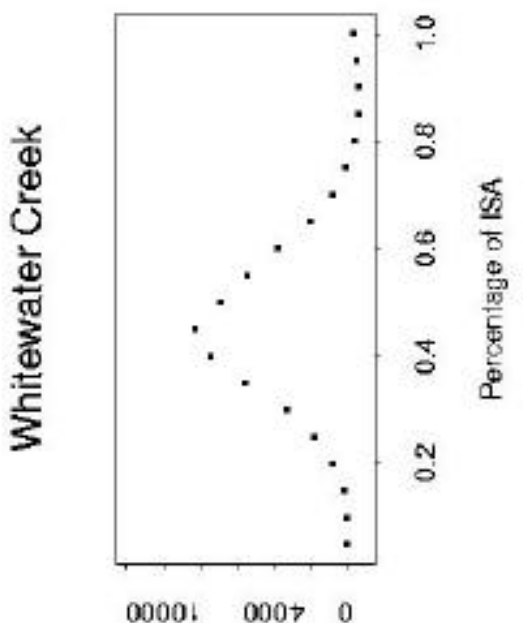

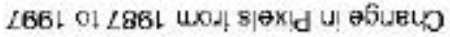

Figure 6. Dotplots indicating differences in number of ISA pixels from 1987 to 1997 for the different watersheds (Line, Line / Flat, Whitewater creeks, and the entire drainage area (LFW)). Differences were calculated for intervals of ISA percentages ( 0 to 1 representing 0 to 100\%) of width $5 \%$, e.g., the value plotted at 1.0 relates to the $95 \%$ to $100 \%$ interval of ISA percentages. 